\title{
EDUCOMUNICAÇÃO NA ESCOLA: NARRATIVA DE UMA EXPERIÊNCIA PEDAGÓGICA ${ }^{1}$ \\ EDUCOMUNICATION IN SCHOOL: NARRATIVE OF A PEDAGOGICAL EXPERIENCE
}

\author{
Sandra Beatriz Silva da Costa ${ }^{2}$, Taís Steffenello Ghisleni ${ }^{3}$ e Janaína Pereira Pretto Carlesso ${ }^{4}$
}

\section{RESUMO}

O presente estudo tem por objetivo analisar o projeto interdisciplinar "Nossa Vida, Nossa Vila", desenvolvido pela pesquisadora em uma escola da rede pública municipal da região central do RS, estabelecendo os elos da prática educativa narrada com os pressupostos da educomunicação no ambiente escolar. Do mesmo modo, pretende verificar em que medida a mesma colabora para a formação de uma consciência crítica e cidadã dos sujeitos envolvidos, assim como, analisar se a participação dos alunos acontece de forma colaborativa e identificar quais as ferramentas comunicativas utilizadas no desenvolvimento do projeto. Sendo que, o tipo de estudo realizado é de cunho qualitativo e usa a análise da narrativa de "experiência do vivido". Analisando a experiência educativa tida como objeto deste estudo, constata-se que, foram usadas inúmeras ferramentas "educomunicativas", assim como, foi possível estabelecer relações colaborativas por parte dos sujeitos envolvidos, através da participação democrática, crítica e criativa. Logo, o processo apresentou muitas características imprescindíveis para a educomunicação, conforme o aporte teórico estudado. Durante e após a realização do trabalho, os alunos apresentaram comportamentos e tiveram iniciativas que demonstraram um avanço na tomada de consciência enquanto cidadãos.

Palavras-chave: educação; diálogo; cidadania; comunicação; educomunicação.

\section{ABSTRACT}

The present study aims to analyze the interdisciplinary project "Our Life, Our Village", developed by the present researcher in a public school from the central region of Rio Grande do Sul State, establishing the links of educational practice narrated from the assumptions of educommunication in the school environment. Similarly, it intends to verify to what extent it collaborates for the formation of a critical and citizen consciousness of the subjects involved, as well as to analyze whether the participation of students happens collaboratively and to identify which communicative tools used in the development of the project. Hence, the type of study performed is qualitative in nature and uses the analysis of the narrative of "experience of the lived". Analyzing the educational experience seen as the object of this study, it is observed that numerous "educommunicative" tools were used, as well as, it was possible to establish collaborative relationships on the part of the subjects involved, through democratic, critical and creative participation. Therefore, the process presented many essential characteristics for educommunication, according to the theoretical

\footnotetext{
${ }^{1}$ Trabalho resultante da Disciplina Educomunicação do Mestrado Acadêmico em Ensino de Humanidades e Linguagens MEHL da Universidade Franciscana UFN.

2 Aluna do Mestrado em Ensino de Humanidades e Linguagens Universidade da Universidade Franciscana - UFN. E-mail: sandrartescosta@gmail.com

3 Doutora. Professora do Curso de Publicidade e Propaganda e do Mestrado em Humanidades e Linguagens da Universidade Franciscana - UFN. E-mail: taisghisleni@yahoo.com.br

4 Orientadora. Doutora. Professora do Curso do Mestrado em Ensino de Humanidades e Linguagens Universidade da Universidade Franciscana - UFN. E-mail: janapcarlesso@yahoo.com.br
} 
contribution studied. During and after the work, the students presented behaviors and had initiatives that demonstrated an advance in awareness as citizens.

Keywords: education; dialogue; citizenship; communication; educommunication.

\section{INTRODUÇÃO}

O campo da educomunicação é relativamente novo e delineou-se gradativamente, a partir de vários estudos realizados por ativistas da educação/comunicação, novos sentidos, principalmente, durante a década de noventa. Para Soares (2014), alguns autores consideram educomunicação como sinônimo de educação diante dos meios de comunicação; outros, como prática mais moderna da educação midiática. Em 1999, o conceito atingiu um patamar mais complexo, passando a designar um campo de intervenção social na interface entre comunicação e a educação. Evidenciando-se, conforme Soares (2014), a essencialidade do direito à comunicação em todos os espaços da vida social, incluindo o educacional.

Um direito "à palavra" no ponto de vista freireano, que veio a somar forças na luta pela democratização das formas de expressão. Concepção esta, validada pelo Núcleo de Comunicação e Educação da USP que, junto a especialistas de vários países latino-americanos, realizaram estudos no período entre 1997 a 1999. Elas vieram a agregar ao ensino um leque de novas possibilidades no enfrentamento dos desafios contemporâneos, gerados pela globalização e a massificação das culturas. Fatores que geram maior urgência na formação de sujeitos críticos, reflexivos, com autonomia para reconhecerem-se, conhecerem seu meio, atuarem nele e, nesta relação, na visão de Freire (1984), transformarem-se enquanto sujeitos, mantendo uma busca permanente de si mesmos e reafirmando continuamente sua responsabilidade em relação a seu contexto.

A condição comunicacional contemporânea abre novos cenários e opções educativas, questões estas discutidas por Gomes (2014), no artigo "Entre Telas: novos papéis comunicativos e educativos dos cidadãos", que reforça a necessidade do "público", além de ser crítico, também ser ativo diante dos diferentes meios de comunicação e seus conteúdos. A busca para atingir este nível de interpretação e participação apresenta-se como um complexo desafio educativo e comunicativo. O uso de alguns recursos didáticos sugeridos por este novo campo de estudos, há muito tempo, já se constituíam como ferramentas pedagógicas, principalmente na área das ciências humanas, porém, o que faz toda a diferença é a perspectiva na qual as ações do processo educativo são fundamentadas.

Segundo Martín-Barbero (2000), em seu artigo, “Desafios Culturais da Comunicação à Educação", a importância estratégica da utilização e uso criativo e crítico dos meios audiovisuais e das tecnologias, conjuntamente com uma prática coerente, que ultrapasse a linearidade e atinja uma forma descentralizada e plural, na perspectiva da formação de sujeitos capazes de compreender o seu contexto e agir de forma autônoma, colaborando para a construção de uma sociedade cidadã. Assim, problematizar uma 
experiência pedagógica coordenada pela pesquisadora, após trinta e quatro anos atuando como professora de artes da rede pública municipal de ensino constitui-se em uma preciosa oportunidade de (re) significar sua "práxis", sob o prisma da educomunicação e colocá-la a disposição da comunidade científica para que novos diálogos possam surgir e outras práticas possam ser mobilizadas.

No estudo realizado, procurou-se compreender o conceito e os pressupostos do campo da educomunicação, seguida pela narrativa de uma prática pedagógica e sua posterior análise através das teorias estudadas. Para Freire (1980), a educação é comunicação, é diálogo, na medida em que não é transferência de saber, mas um encontro de sujeitos interlocutores que buscam a significação dos significados.

A partir da perspectiva freireana, (KAPLÚN, apud DRUETTA, 2014), identifica-se três modelos de comunicação educativa: o bancário, o individualizado e a dialógica, defendida por Kaplún (1993), em consonância com Freire, propõe uma ruptura com os anteriores, na medida em que enfatiza o diálogo como processo desencadeador de mudança da realidade e reconhece o papel ativo dos sujeitos envolvidos, responsáveis pela sua formação/ transformação social.

Para Bacega (2009), os sentidos sociais, configurados e reconfigurados na práxis, têm na comunicação/educação o lócus privilegiado de sua instituição, porque é aí que se dá claramente o embate das 'agências' de socialização mídia versus escola e família, com o objetivo de revestir de significados os signos em circulação. Evidenciando-se, assim, a importância dos processos educomunicativos e da apropriação dos seus conceitos, para que seus objetivos sejam efetivados.

A partir de tais considerações iniciais, o objetivo do presente estudo foi analisar o projeto "Nossa Vida, Nossa Vila”, desenvolvido pela pesquisadora em uma escola da rede pública municipal com alunos do Ensino Fundamental, estabelecendo os elos da prática educativa narrada com os pressupostos da educomunicação. Pretendeu-se também, verificar em que medida a prática pedagógica narrada colaborou para a formação de uma consciência crítica e cidadã dos sujeitos envolvidos, analisar se a participação dos alunos se deu de forma colaborativa e criativa, identificar se as relações interpessoais estabelecidas na realização do projeto possibilitaram a participação democrática dos alunos.

\section{EDUCAÇÃO/COMUNICAÇÃO NUMA PERSPECTIVA FREIREANA}

Numa perspectiva freireana segundo Lima (1984), a educação e comunicação são dois conceitos tão interligados que podem ser considerados sinônimos, provavelmente, porque o único trabalho em que Freire se refere exclusivamente a comunicação foi no ensaio "Extensão ou Comunicação", escrito em 1968 para o "Instituto de Capacitación e Investigación en Reforma Agraria” (ICIRA), onde faz uma crítica ás atividades de extensão realizadas pelos agrônomos chilenos naquele período e ao mesmo tempo pela maneira como os estudos norte-americanos em comunicação eram difundidos na América Latina. Nele, Freire esclarece que extensão, implica transmissão, transferência, invasão 
(cultural), e não comunicação entendida como “coparticipação de Sujeitos no ato de conhecer”. Lima (1984, p. 74) considera o ensaio de extrema relevância, por revelar a base filosófica da epistemologia de Freire e do conceito de educação como 'ação cultural', já que para Freire "o mundo social humano não existiria se não fosse um mundo capaz de comunicar" e em outro estudo diz que "impedir a comunicação equivale a reduzir o homem à condição de coisa (...) somente através da comunicação que a vida humana adquire significado".

Em “Comunicação e Cultura: As Ideias de Paulo Freire”, Lima (1984) discorre sobre o contexto social das ideias de Freire, a importância dos seus conceitos de comunicação e cultura e o quanto estes, abrem novas possibilidades para os estudos da comunicação sob várias perspectivas. O autor evidencia no conceito de comunicação em Freire, a concepção de ser humano enquanto ser de relação, entre si e com o mundo. Enfatiza que, para Freire comunicação implica em coparticipação dos sujeitos no ato de pensar, sendo o objeto de conhecimento, o seu mediador. Desta forma, reafirma que, a comunicação, na concepção freireana, é compreendida como "uma interação entre sujeitos iguais e criativos" fundada no diálogo, que para ele não significa invasão, manipulação, mas, sim o encontro de amor entre pessoas que, mediadas pelo mundo, o transformam (FREIRE, apud, LIMA, 1984, p. 65). Evidenciando-se a dimensão política do conceito.

A "ação cultural dialógica para a liberdade e a revolução dialógica" são os caminhos propostos por Freire para que os homens e as sociedades possam reconquistar sua verdadeira voz num mundo desumanizado. Sendo a cultura, entendida como resultado da práxis e do trabalho humano em sua relação dialética com o mundo, ela compreende o universo simbólico e abrangente em que homens atuam como seres conscientes. A cultura não é uma coisa, mas uma relação, um processo dialético em permanente movimento, criado pelo homem, mas que ao mesmo tempo, a cria (LIMA, 1984). O ímpeto criador existe em todo o homem pela sua própria inconclusão, sendo sua principal característica, a reflexão (FREIRE, 1984).

A partir da ótica freireana, (KAPLÚN, apud DRUETTA, 2014), descreve três modelos de comunicação educativa: o bancário; o modelo focalizado nos efeitos e o da educação transformadora. O primeiro, segue a lógica das indústrias culturais, reprodutoras dos sistemas existentes e do consumo. Nela, o professor é um transmissor de informações, as avaliações são usadas como castigo e a mídia também se colocam como unidirecional, não leva em conta a capacidade de interação entre os receptores, produzindo a massificação dos processos comunicativos.

O segundo modelo, se coloca no outro extremo, o ensino individualizado, que orienta os alunos receptores ao consumo de bens e serviços. Não possibilita interpretações individuais, já que o aluno segue instruções programadas para a aquisição do "conhecimento".

O terceiro modelo defendido por Kaplún (1993), em consonância com a perspectiva freireana, propõe uma ruptura com os anteriores, na medida em que enfatiza o diálogo como processo desencadeador de mudança da realidade. Reconhece o papel ativo dos sujeitos envolvidos, principalmente 
dos educandos, que passam a ser também responsáveis pela sua formação e pela transformação social. Este modelo se valoriza o processo educativo, em sua ação transformadora e geradora de sentidos.

Para Bacega (2009), os sentidos sociais, configurados e reconfigurados na práxis, têm na comunicação/educação o lócus privilegiado de sua instituição. Isso ocorre porque é aí que se dá claramente o embate das 'agências' de socialização mídia versus escola e família, com o objetivo de revestir de significados os signos em circulação Evidenciando-se assim, a importância dos processos educomunicativos e do entendimento dos seus princípios para que seus objetivos sejam conquistados. Pode-se evidenciar, então, que as concepções de homem/comunicação/educação/cultura de Paulo Freire foram imprescindíveis para a estruturação do campo de estudos da educomunicação.

\section{EDUCOMUNICAÇÃO: CONCEITO E PRINCÍPIOS}

Na década de 1980, a UNESCO já referendava o uso da palavra "educomunicação" para designar uma prática definida na Europa como 'Media Education" que, de acordo com Soares (2014), era compreendida como, educação para a recepção crítica dos meios de comunicação. Na américa latina, com a incorporação de uma perspectiva dialética, além de discutir o impacto das mensagens, passou-se a considerar, "o modo como as audiências reagiam e se articulavam ao receber e ressignificar os conteúdos midiáticos".

Durante a década de 1990, no Brasil, algumas ONGs e serviços de extensão das universidades ressaltaram que o exercício de "produzir comunicação" de forma democrática e participativa, aplicados em suas práticas de formação para jovens e crianças, agregava um diferencial, aos conceitos anteriores.

O Núcleo de Comunicação e Educação (NCE) da USP, a partir de1999, adotou o termo educomunicação, com o mesmo significado. Para chegar a este consenso, foram pesquisados trabalhos desenvolvidos em vários países da América Latina (SOARES, 2014). Conceituando então, este campo de intervenção social como "o conjunto de ações voltadas ao planejamento de práticas destinadas a criar e desenvolver ecossistemas comunicativos abertos e criativos, em espaços educativos, garantindo, crescentes possibilidades de expressão a todos os membros das comunidades educativas (SOARES, 2003, apud SOARES, 2014, p. 36).

Outro conceito que precisa ser abordado é o de "ecossistema comunicativo", usado para "designar as teias de relações das pessoas que convivem nos espaços onde esses conjuntos de ações são implementados" (SOARES, 2014). E, conforme o autor, é imprescindível que estas relações sejam "inclusivas, democráticas, midiáticas e criativas" e, obviamente, muitas dificuldades se apresentam diante da determinação de um grupo que quer mobilizar ações com tais características. O maior obstáculo tem sido a resistência às mudanças nos processos de relacionamento na maioria dos ambientes educativos. E vai além, afirmando que, para a construção 
deste novo "ecossistema", é imprescindível "clareza conceitual, planejamento, acompanhamento e avaliação" (MARTÍN-BARBERO, 2000; SOARES, 2014).

Para que, ecossistemas comunicativos, possam ser criados, faz-se necessário uma pedagogia de projetos voltados para o diálogo educomunicativo, para que as novas gerações possam ler criticamente o mundo dos meios de comunicação, mas também, de promover as próprias formas de expressão (SOARES, 2014).

A educomunicação faz sua opção pela construção de modalidades abertas e criativas de relacionamento, possibilitando a legitimidade do diálogo como metodologia de ensino, aprendizagem e convivência. Assim, nesta perspectiva, a relação dialógica não é dada pela tecnologia e, sim, pelo tipo de convívio humano e trata-se de uma decisão ético, político, pedagógica (SOARES, 2014). Ainda, o grande desafio para desenvolver ações pedagógicas no ensino regular, na perspectiva da educomunicação, provém da necessidade de estabelecer um processo democrático, rompendo com o modelo vigente, verticalista e autoritário.

\section{ASPECTOS METODOLÓGICOS}

A pesquisa realizada é bibliográfica de caráter qualitativo, (SAMPIERI; COLLADO; BAPTISTA, 2006) associada à técnica de pesquisa análise de narrativa do vivido, que decorrem de uma situação vivencial e não experimental e podem ser chamadas de "narrativas de experiências educativas", das quais, podem-se extrair lições que valham como conhecimentos produzidos a posteriori, resultando do embate entre a experiência e os estudos teóricos realizados após a experiência narrada (LIMA; GERALDI; GERALDI, 2015).

Para contemplar os conceitos de educação/comunicação e para identificar os pressupostos educomunicativos na experiência educativa narrada vivenciada pela pesquisadora no projeto interdisciplinar "Nossa Vida, Nossa Vila", realizado no período de 2007 a 2009, com alunos dos anos finais $\left(6^{\circ}\right.$ ao $\left.9^{\circ}\right)$, do Ensino Fundamental (EF) e Educação de Jovens e Adultos (EJA) de uma escola de ensino fundamental da rede pública municipal de uma cidade localizada na região central do Estado do Rio Grande do Sul, foi utilizado o aporte teórico dos seguintes autores: Soares (2014), Freire (1984), Barbero (2000), Bacega (2009), Gomez (2009), Sampiere, Collado e Batista (2006), Lima (1984), Lima, Geraldi e Geraldi (2015) e Druetta (2014).

A escolha do projeto "Nossa Vida, Nossa Vila" objeto da análise da narrativa desse estudo, deu-se pela sua relevância, para os sujeitos envolvidos e para a rede de ensino. O mesmo iniciou nas aulas de Educação Artística (Artes), com a participação intensa e colaborativa dos alunos e, posteriormente, dos professores das outras disciplinas, configurando-se como um projeto interdisciplinar, extremamente, significativo para os sujeitos envolvido. Cabe apontar que a interdisciplinaridade se 
caracteriza pela intensidade das trocas entre os especialistas e pelo grau de integração real das disciplinas no interior de um mesmo projeto de pesquisa (JAPIASSÚ, 1976).

\section{RESULTADOS E DISCUSSÕES}

\section{NARRATIVA DE UMA PRÁTICA PEDAGÓGICA}

A prática pedagógica deste estudo refere-se ao Projeto interdisciplinar "Nossa Vida, Nossa Vila", realizada no período de 2007 a 2009, com alunos dos anos finais do EF e EJA, que surgiu a partir dos diálogos em sala de aula, onde os alunos e a professora de artes, (disciplina de educação artística), discutiam sobre várias questões do cotidiano das comunidades próximas à escola. Como estavam próximas as comemorações de aniversário do município e é costume das escolas abordarem o assunto no período, buscou-se contextualizar com as atividades oficiais, subtemas significativos, instigantes e se diferenciasse do que já havia sido feito nos anos anteriores. O consenso deu-se pela escolha de uma "Cidade Real", com o cotidiano deles, dos seus endereços e seus trajetos. Através do projeto, pode-se conhecer melhor a vida de cada aluno, incorporar ao currículo alguns dados coletados e, ainda, legitimá-los enquanto objeto de estudo, na sala de aula.

O projeto foi realizado nas seguintes etapas: no primeiro momento, nas aulas de educação artística, os alunos reuniram-se nas suas próprias turmas e depois com os colegas das demais turmas e anos. O objetivo inicial era analisar a sua vila e enumerar os aspectos positivos e suas fragilidades, na opinião do grupo e identificar as possíveis medidas que poderiam ser efetivadas pela comunidade local, poder público e outras instituições, na busca de melhorias para a comunidade.

Assim, foram delineando-se uma série de atividades que foram ganhando corpo e configurou-se como um projeto interdisciplinar, com a adesão de outros professores de $6^{\circ}$ a $9^{\circ}$ ano e EJA. Os participantes da pesquisa fizeram registros fotográficos, entrevistas com moradores e aguçavam o olhar para as pessoas, infraestrutura do local, necessidades, fatos cotidianos, expectativas, necessidades, enfim para a sua vila e sua vida. À medida que os alunos coletavam os dados, nas aulas e nos períodos entre os turnos, estes eram confrontados com os dos colegas. Reunidos em grupos, as questões foram amadurecendo, e uma lista única para cada vila ia se desenhando, com o entendimento que novos fatos poderiam modificá-las constantemente. Nas aulas de artes, os grupos escolheram uma ou mais modalidades artísticas para representar e apresentar suas discussões, estudos e propostas, aos demais colegas da turma. As apresentações geraram debates, relações, e novos estudos. As atividades desenvolvidas foram registradas em vídeo e compartilhadas por todos os alunos de $6^{\circ}$ a $9^{\circ}$ ano do EF e EJA da escola. Nas demais disciplinas foram abordadas outros enfoques, como pesquisa as doenças mais comuns, chás e seus efeitos segundo tradição dos familiares, gráficos elaborados pelos alunos para registrar as pesquisas. 
$\mathrm{Na}$ EJA, além dessas atividades, foi realizada uma pesquisa sobre a procedência dos moradores da comunidade, procurando saber, principalmente se vieram de área rural ou urbana, costumes, conhecimentos populares em geral, registros literários de suas trajetórias pessoais e perspectivas futuras. Também foi criada coletivamente uma "instalação" (modalidade artística das artes visuais), em forma de túnel, no corredor da escola, representando as alegrias e as tristezas dos moradores, de acordo com as cores e formas usadas.

A cada final de ano letivo, de 2007, 2008 e 2009, os trabalhos desenvolvidos eram compartilhados com a comunidade escolar através de mostras didáticas. Estas exposições, geravam reflexões e novas ideias, possibilitando várias ações educativas como: A História da Escola, Os Quatro Elementos Essenciais à Vida, Autoconhecimento e Ação cidadã. Estes blocos de atividades, inclusive o projeto Nossa Vida, Nossa Vila, foram considerados como um circuito de ações pedagógicas denominadas "Cuidando da Vida", tendo representação numa caminhada na comunidade e no município.

Segundo Thiesen (2008), uma perspectiva interdisciplinar na educação possibilita o aprofundamento da compreensão da relação entre teoria e prática, contribui para uma formação mais crítica, criativa e responsável e coloca escola e educadores diante de novos desafios tanto no plano ontológico quanto no plano epistemológico.

A interdisciplinaridade é um movimento importante de articulação entre o ensinar e o aprender. Compreendida como formulação teórica e assumida enquanto atitude tem a potencialidade de auxiliar os educadores e as escolas na ressignificação do trabalho pedagógico em termos de currículo, de métodos, de conteúdos, de avaliação e nas formas de organização dos ambientes para a aprendizagem. Os professores são protagonistas desta mudança, pois a partir do momento que se tornam atuantes na sua prática diária podem planejar de maneira coletiva e interdisciplinar. O currículo escolar deve ser visto como um processo em constante construção, onde os sujeitos deste processo devem estar inseridos no contexto e nas decisões a serem tomadas compreendidas como possível e necessária de se materializar na seleção do que e como ensinar, pela comunidade e pela escola, como forma de contribuir na transformação de uma realidade social (BRAZ et al, 2018).

\section{CONSIDERAÇÕES FINAIS}

A análise do estudo realizado aponta que um dos desafios enfrentados pelos profissionais que atuam no ensino regular ao tentar estabelecer "ecossistemas comunicativos", é que estes, seguem uma perspectiva oposta a, ao que parece ainda vigente na maioria dos estabelecimentos públicos de ensino. Desta forma, pode-se considerar relevante que, iniciativas no ambiente educacional, enfrentem os desafios e operacionalizem a formação de ecossistemas comunicativos, como foi o caso do projeto interdisciplinar "Nossa Vida, Nossa Vila", possibilitando aos sujeitos envolvidos, participação de forma democrática e colaborativa, ampliando seu potencial criativo e crítico. E também, oportunizando 
aos alunos expressarem-se através do uso de vários recursos comunicativos, artísticos, tecnológicos, assim como, nesse processo ir criando uma identidade pessoal e ajudando a construir a identidade da comunidade na qual está inserido, responsabilizando-se como cidadão, por esta construção. Percebemos, que a prática educomunicativa esteve presente durante todo o projeto, mesmo que os participantes não tivessem ainda o conhecimento mais detalhado da teoria que estavam aplicando na prática.

Realizar este estudo foi de especial importância para a pesquisadora, pela oportunidade de (re) significar sua atuação docente à luz do conhecimento científico no campo da educomunicação. Diante dos resultados, pode-se considerar que as ações pedagógicas narradas demonstraram uma grande identificação com os pressupostos da educomunicação e podem inspirar outras ações em espaços educativos tanto no ensino regular como não regular, em ambientes formais ou informais. Da mesma forma pode influenciar outros estudos que aproveitem narrativas de experiências semelhantes a esta.

\section{REFERÊNCIAS}

BACCEGA, Maria Aparecida: Comunicação/educação e a construção de nova variável histórica. Trabalho apresentado no II Libercom, Mesa: Os desafios da Educomunicação na realidade escolar: a teoria aplicada aos projetos práticos. Comunicação \& Educação: Revista do Curso de Gestão de Processos Comunicacionais, São Paulo, v. 14, n. 3, p. 19-28, set./dez. 2009 Disponível em: https://bit.ly/ 37os88k. Acesso em 09 em dez. 2019.

BRAZ, J. C.; SANTOS, E. A. G.; ZUCOLOTTO, M. P. R; CARLESSO, J. P. P. Interdisciplinaridade, currículo e formação de professores: no contexto da educação do campo. Revista Eletrônica Científica Ensino Interdisciplinar, Mossoró, v. 4, n. 12, 2018.

DRUETTA, Delia Crovi. A trama reticular da educação. Uma perspectiva desde a comunicação. São Paulo: Paulinas, 2014.

FREIRE, Paulo. Educação e Mudança. 8. ed. São Paulo: Paz e Terra, 1984.

GOMES, Guillermo Orosco. Entre telas: novos papéis comunicativos e educativos dos cidadãos. In: APARICI, Roberto (org.) Educomunicação: para além do 2.0. 3. ed. São Paulo: Paulinas, 2014.

JAPIASSU, Hilton. Interdisciplinaridade e patologia do saber. Rio de Janeiro: Imago, 1976.

KAPLÚN, Mário. Uma Pedagogia da Comunicação. In: APARICI, Roberto (org.) Educomunicação: para além do 2.0. 3. ed. São Paulo: Paulinas, 2014. 
LIMA, Maria E. de Castro; GERALDI, Corinta Maria Grisolia; GERALDI, João Wanderley. O Trabalho com Narrativas na Investigação em Educação. Educação em Revista, Belo Horizonte, v. 31, n. 1, p. 17-44, Janeiro-Março 2015.

LIMA, Venício Artur de. Comunicação e Cultura: as ideias de Paulo Freire. 2. ed. Rio de Janeiro: Paz e Terra, 1984.

MARTÍN-BARBERO. Jesus. Desafios culturais da comunicação à educação. Comunicação \& Educação, n. 18, p.51-61, 30 set. 2000.

SAMPIERI, R H., COLLADO, C.F; BAPTISTA Ma. P. Metodología de la Investigación. 4. ed.. Mc GRAW-HILL, México, 2006.

SOARES, Ismar de Oliveira. A Educação na América Latina: apontamentos para uma história em construção. In: APARICI, Roberto (org.) Educomunicação: para além do 2.0. 3. ed. São Paulo: Paulinas, 2014.

SOARES, Ismar de Oliveira. Educomunicação e Educação: o conceito, o profissional, a aplicação: contribuições para a reforma do ensino médio. In: APARICI, Roberto (org.) Educomunicação: para além do 2.0. 3. ed. São Paulo: Paulinas, 2014.

THIESEN, J. S. A interdisciplinaridade como um movimento articulador no processo ensino-aprendizagem. Rev. Bras. Educ., v. 13, n. 39, p. 545-554, 2008. 